\title{
PROYEKSI INDEKS PEMBANGUNAN MANUSIA DI INDONESIA MENGGUNAKAN METODE STATISTICAL PARABOLIC DALAM MENYONGSONG REVOLUSI INDUSTRI 4.0
}

\author{
Ika Okta Kirana1), Zulaini Masruro Nasution²), Anjar Wanto3) \\ 123 Program Studi Teknik Informatika, STIKOM Tunas Bangsa Pematangsiantar \\ Email: ikaoktakirana@stikomtb.ac.id, zulaini@amiktunasbangsa.ac.id, anjarwanto@amiktunasbangsa.ac.id
}

\begin{abstract}
ABSTRAK
Indeks Pembangunan Manusia (IPM) merupakan indikator yang sangat penting dalam mengukur keberhasilan sebuah negara dalam membangun kualitas hidup penduduk / masyarakat nya, termasuk Indonesia. Ekonomi global saat ini sedang pada titik puncak perubahan besar yang sebanding besarnya dengan munculnya revolusi industri 4.0. Penentuan peringkat atau level pembangunan dan ekonomi dari suatu wilayah atau negara dapat dilihat dari Indeks Pembangunan Manusia (IPM). Karena begitu pentingnya Indeks Pembangunan Manusia (IPM), maka perlu dilakukan proyeksi tingkat perkembangan IPM di tahun-tahun selanjutnya, agar pemerintah Indonesia memiliki referensi dan acuan yang jelas untuk menentukan kebijakan ataupun membuat langkah-langkah strategis yang tepat agar Indeks Pembangunan Manusia (IPM) jangan sampai menurun di masa yang akan datang, bahkan meningkat pada tiap tahunnya. Data yang akan diproyeksi pada penelitian ini adalah data Indeks Pembangunan Manusia (IPM) tahun 2010-2018. Sumber data diambil dari Badan Pusat Statistik (BPS) Indonesia. Pada penelitian ini, metode proyeksi yang digunakan untuk memproyeksi data IPM di Indonesia adalah Statistical Parabolic Projection (Trend Parabolik). Akan tetapi sebelum menggunakan metode ini, data terlebih dahulu harus dihitung menggunakan metode jumlah kuadrat terkecil agar perhitungannya lebih teliti. Setelah dilakukan perhitungan, diperoleh selisih antara data asli IPM dengan data hasil proyeksi sangat dekat sekali, dengan tingkat MSE sebesar 0,01659. Sehingga disimpulkan bahwa metode Trend Parabolik baik digunakan untuk melakukan proyeksi. Oleh karena itu hasil penelitian ini adalah proyeksi Indeks Pembangunan Manusia (IPM) di Indonesia untuk tahun 2019 hingga tahun 2027.
\end{abstract}

Kata kunci: Proyeksi, Indeks Pembangunan Manusia, Trend Parabolik, Revolusi Industri 4.0

\begin{abstract}
The Human Development Index (HDI) is a very important indicator in measuring the success of a country, including the people of Indonesia, including Indonesia. The global economy is currently at a point of major change compared to the comparison of the 4.0 industrial revolution. Ranking or level of development and economy of a region can be seen from the Human Development Index (HDI). Because it is so important the Human Development Index (HDI), it is necessary to project the level of $\mathrm{HDI}$ development in the coming years, so that the Indonesian government has clear strategic steps for making appropriate strategic steps for the Human Development Index $(H D I)$ is not to increase in the future, event is increasing at any time. The data for this study is the Human Development Index (HDI) data for 2010-2018. Data sources were taken from the Indonesian Central Bureau of Statistics (BPS). In this study, the research method used for the HDI data project in Indonesia is the Parabolic Projection Statistics (Parabolic Trend). However, before using this method, the data must be calculated using the increasing number of squares so that the calculation is more precise. After calculation, the difference between the original HDI data and the projection data is very close, with the MSE level of 0.01659. Parabolic Trends Are Good For Projection. Therefore, the results of this study are experiments on the Human Development Index (HDI) in Indonesia for 2019 until 2027.
\end{abstract}

Keywords : Projection, Human Development Index, Parabolic Trend, 4.0 Industrial Revolution 


\section{PENDAHULUAN}

Pembangunan maupun ekonomi global saat ini sedang pada titik puncak perubahan besar yang sebanding besarnya dengan munculnya revolusi industri 4.0. Salah satu Paradigma pembangunan di Indonesia yang saat ini sedang berkembang adalah pertumbuhan ekonomi yang dapat dilihat dari tingkat kualitas hidup manusia yang diukur dengan indeks pembangunan manusia [1]. Indeks Pembangunan Manusia (IPM) merupakan hal yang sangat penting dalam pengukuran keberhasilan negara sebagai upaya membangun kualitas hidup penduduk/masyarakat pada sebuah wilayah/negara, termasuk Indonesia. IPM juga menjelaskan bagaimana masyarakat/penduduk pada suatu wilayah/negara dapat mengakses hasil pembangunan untuk memperoleh pendapatan, pendidikan, kesehatan, dan sebagainya [2]. Indeks Pembangunan Manusia (IPM) juga merupakan indeks komposit yang dipengaruhi oleh indikator kesehatan yang diwakili oleh angka harapan hidup, indikator pendidikan yang di wakili oleh rata-rata lama sekolah dan indikator ekonomi yang diwakili oleh daya beli masyarakat [3]. Indeks Pembangunan Manusia (IPM) disusun sebagai salah satu dari indikator alternatif, selain pendapatan nasional per kapita, untuk menilai keberhasilan pembangunan yang dilaksanakan oleh suatu Negara [4]. Salah satu hal yang melatar belakangi perlunya kepedulian terhadap pembangunan manusia karena banyak negara yang sedang berkembang termasuk Indonesia, telah berhasil meningkatkan pertumbuhan ekonomi, akan tetapi tidak mampu meminimalisir kesenjangan ekonomi, sosial dan kemiskinan [5].

Karena begitu pentingnya Indeks Pembangunan Manusia (IPM) di negara Indonesia, maka perlu dilakukan proyeksi (peramalan) tingkat perkembangan IPM di tahun-tahun selanjutnya, agar pemerintah Indonesia memiliki referensi dan acuan yang jelas untuk menentukan kebijakan ataupun membuat langkah-langkah strategis yang tepat agar Indeks Pembangunan Manusia (IPM) di Indonesia jangan sampai menurun di masa yang akan datang, bahkan meningkat pada tiap tahunnya. Proyeksi seyogyianya adalah dugaan mengenai terjadinya suatu keadaan di waktu yang akan datang. Proyeksi sangat membantu dalam kegiatan perencanaan dan pengambilan keputusan akan suatu kebijakan [6]. Baik dilakukan oleh pemerintah maupun swasta. Analisis pada sebuah proyeksi sangat penting dilakukan pada sebuah penelitian, agar penelitian menjadi lebih tepat dan terarah [7]. Oleh karena itu dibutukan analisis yang baik dengan menggunakan metode-metode yang sudah teruji, agar keakuratan yang dihasilkan dapat benar-benar dipertanggungjawabkan. Pada penelitian ini, metode proyeksi yang digunakan untuk melihat perkembangan IPM di Indonesia adalah Statistical Parabolic Projection (Trend Parabolik). Metode ini sering digunakan untuk memproyeksi data timesseries, karena tingkat error (kesalahan) yang lebih kecil dibandingkan metode-metode matematika statistik yang lain seperti Arithmatic Stright Line, Arithmatic Geometric Curve, Stright Line, dan Statistical Semi Log.

Berdasarkan data Badan Pusat Statistik, secara garis besar Indeks Pembangunan Manusia tahun 2010 hingga tahun 2018 mengalami peningkatan, kendati tidak terlalu signifikan. Seperti pada tahun 2018 tingkat Indeks Pembangunan Manusia di Indonesia sebesar 70,81, sedangkan pada tahun 2018 sebesar 71,39 atau meningkat sebesar 0,58 [8]. Untuk lebih jelasnya dapat dilihat pada Tabel 1 berikut ini.

Tabel 1. Data Indeks Pembangunan Manusia di Indonesia

\begin{tabular}{llllllllll}
\hline \multirow{1}{*}{ Provinsi } & \multicolumn{8}{c}{ In d e k s } & P m b a n g u n a n M a n u s i a \\
\cline { 2 - 10 } & $\mathbf{2 0 1 0}$ & $\mathbf{2 0 1 1}$ & $\mathbf{2 0 1 2}$ & $\mathbf{2 0 1 3}$ & $\mathbf{2 0 1 4}$ & $\mathbf{2 0 1 5}$ & $\mathbf{2 0 1 6}$ & $\mathbf{2 0 1 7}$ & $\mathbf{2 0 1 8}$ \\
\hline A c e h & 67.09 & 67.45 & 67.81 & 68.30 & 68.81 & 69.45 & 70.00 & 70.60 & 71.19 \\
Sum. Utara & 67.09 & 67.34 & 67.74 & 68.36 & 68.87 & 69.51 & 70.00 & 70.57 & 71.18 \\
Sum. B a rat & 67.25 & 67.81 & 68.36 & 68.91 & 69.36 & 69.98 & 70.73 & 71.24 & 71.73 \\
Ria u & 68.65 & 68.90 & 69.15 & 69.91 & 70.33 & 70.84 & 71.20 & 71.79 & 72.44 \\
Jamb i & 65.39 & 66.14 & 66.94 & 67.76 & 68.24 & 68.89 & 69.62 & 69.99 & 70.65 \\
Sum. Se Iatan & 64.44 & 65.12 & 65.79 & 66.16 & 66.75 & 67.46 & 68.24 & 68.86 & 69.39 \\
B engkulu & 65.35 & 65.96 & 66.61 & 67.50 & 68.06 & 68.59 & 69.33 & 69.95 & 70.64 \\
Lampung & 63.71 & 64.20 & 64.87 & 65.73 & 66.42 & 66.95 & 67.65 & 68.25 & 69.02 \\
Ke p. Babel & 66.02 & 66.59 & 67.21 & 67.92 & 68.27 & 69.05 & 69.55 & 69.99 & 70.67 \\
\hline
\end{tabular}




\begin{tabular}{|c|c|c|c|c|c|c|c|c|c|}
\hline \multirow{2}{*}{ Provinsi } & \multicolumn{9}{|c|}{ Indeks Pembangunan Manusia } \\
\hline & 2010 & 2011 & 2012 & 2013 & 2014 & 2015 & 2016 & 2017 & 2018 \\
\hline Ke p. Riau & 71.13 & 71.61 & 72.36 & 73.02 & 73.40 & 73.75 & 73.99 & 74.45 & 74.84 \\
\hline DKI Jakarta & 76.31 & 76.98 & 77.53 & 78.08 & 78.39 & 78.99 & 79.60 & 80.06 & 80.47 \\
\hline Jabar & 66.15 & 66.67 & 67.32 & 68.25 & 68.80 & 69.50 & 70.05 & 70.69 & 71.30 \\
\hline Jateng & 66.08 & 66.64 & 67.21 & 68.02 & 68.78 & 69.49 & 69.98 & 70.52 & 71.12 \\
\hline DI Yogyakarta & 75.37 & 75.93 & 76.15 & 76.44 & 76.81 & 77.59 & 78.38 & 78.89 & 79.53 \\
\hline Jatim & 65.36 & 66.06 & 66.74 & 67.55 & 68.14 & 68.95 & 69.74 & 70.27 & 70.77 \\
\hline Banten & 67.54 & 68.22 & 68.92 & 69.47 & 69.89 & 70.27 & 70.96 & 71.42 & 71.95 \\
\hline B a li & 70.10 & 70.87 & 71.62 & 72.09 & 72.48 & 73.27 & 73.65 & 74.30 & 74.77 \\
\hline NTB & 61.16 & 62.14 & 62.98 & 63.76 & 64.31 & 65.19 & 65.81 & 66.58 & 67.30 \\
\hline NTT & 59.21 & 60.24 & 60.81 & 61.68 & 62.26 & 62.67 & 63.13 & 63.73 & 64.39 \\
\hline Kalbar & 61.97 & 62.35 & 63.41 & 64.30 & 64.89 & 65.59 & 65.88 & 66.26 & 66.98 \\
\hline Kalteng & 65.96 & 66.38 & 66.66 & 67.41 & 67.77 & 68.53 & 69.13 & 69.79 & 70.42 \\
\hline Kalsel & 65.20 & 65.89 & 66.68 & 67.17 & 67.63 & 68.38 & 69.05 & 69.65 & 70.17 \\
\hline Kaltim & 71.31 & 72.02 & 72.62 & 73.21 & 73.82 & 74.17 & 74.59 & 75.12 & 75.83 \\
\hline Kalut & 0.00 & 0.00 & 0.00 & 67.99 & 68.64 & 68.76 & 69.20 & 69.84 & 70.56 \\
\hline Sulut & 67.83 & 68.31 & 69.04 & 69.49 & 69.96 & 70.39 & 71.05 & 71.66 & 72.20 \\
\hline Sulteng & 63.29 & 64.27 & 65.00 & 65.79 & 66.43 & 66.76 & 67.47 & 68.11 & 68.88 \\
\hline Sulsel & 66.00 & 66.65 & 67.26 & 67.92 & 68.49 & 69.15 & 69.76 & 70.34 & 70.90 \\
\hline Sul. Tenggara & 65.99 & 66.52 & 67.07 & 67.55 & 68.07 & 68.75 & 69.31 & 69.86 & 70.61 \\
\hline Gorontalo & 62.65 & 63.48 & 64.16 & 64.70 & 65.17 & 65.86 & 66.29 & 67.01 & 67.71 \\
\hline Sulbar & 59.74 & 60.63 & 61.01 & 61.53 & 62.24 & 62.96 & 63.60 & 64.30 & 65.10 \\
\hline Maluku & 64.27 & 64.75 & 65.43 & 66.09 & 66.74 & 67.05 & 67.60 & 68.19 & 68.87 \\
\hline Mal. U t a ra & 62.79 & 63.19 & 63.93 & 64.78 & 65.18 & 65.91 & 66.63 & 67.20 & 67.76 \\
\hline Pap. B a r a t & 59.60 & 59.90 & 60.30 & 60.91 & 61.28 & 61.73 & 62.21 & 62.99 & 63.74 \\
\hline $\mathrm{Papua}$ & 54.45 & 55.01 & 55.55 & 56.25 & 56.75 & 57.25 & 58.05 & 59.09 & 60.06 \\
\hline Indonesia & 66.53 & 67.09 & 67.70 & 68.31 & 68.90 & 69.55 & 70.18 & 70.81 & 71.39 \\
\hline
\end{tabular}

Sumber : Badan Pusat Statistik (BPS) Indonesia [8]

Berdasarkan tabel 1 dapat dijelaskan bahwa tingkat perkembangan Indeks Pembangunan Manusia di Indonesia cenderung menaik tiap tahunnya. Seperti pada tahun 2017 nilai IPM sebesar 70,81 sedangkan tahun 2018 menjadi 71,39. Berarti terjadi kenaikan sebesar 0,58.

Sebelumnya telah banyak penelitian-penelitian terkait Indeks Pembangunan Manusia atau Trend Parabolik, diantaranya penelitian untuk memprediksi Indeks Pembangunan Manusia menggunakan Decision Tree C4.5 di Kabupaten Kampar, penelitian ini cukup bagus dengan menghasilkan nilai entropy IPM 0,72193 dan gain 0,72193 dimana nilai entropy didapatkan dari IPM level dan kategori yang hasil nilai entropy untuk nilai penjumlahan nilai gain [9]. Selanjutnya dilakukan penelitian untuk Proyeksi Produk Domestik Regional Bruto (PDRB) pemerintah Kabupaten Kudus menggunakan metode Trend Linier, Statistical Parabolic dan Eksponensial. Dari ketiga metode ini, metode yang terbaik untuk memproyeksikan PDRB di Kabupaten Kudus untuk tahun 2017 adalah metode Statistical Parabolic dengan model trend $Y_{c}=46027952,73+5813266,236 X+87516,121$ X2, dengan hasil proyeksi 98.135.114,4 (dalam juta rupiah) [10]. Selanjutnya penelitian untuk menentukan hal-hal yang mempengaruhi Indeks Pembangunan Manusia menggunakan metode regresi data panel [11].

Diharapkan dari hasil proyeksi ini nantinya dapat menjadi referensi dan rujukan untuk membantu pemerintah dalam upaya meningkatkan kualitas hidup masyarakat dalam menyongsong Revolusi Industri 4.0. 


\section{METODOLOGI}

\section{A. Trend Proyeksi}

Metode Proyeksi (Trend Proyeksi) merupakan suatu metode peramalan serangkaian waktu yang sesuai dengan garis tren terhadap serangkaian titik-titik data masa lalu, kemudian diproyeksikan ke dalam peramalan masa depan [12]. Ada beberapa metode proyeksi yang sering digunakan untuk peramalan, antara lain:
1) Arithmetic Straight Line
2) Arithmetic Geometric Curve
3) Statistical Straight Line
4) Statistical Parabolic

a) Arithmetic Straight Line

Metode ini merupakan metode proyeksi yang paling sederhana dengan menggunakan garis lurus aritmatika, dengan rumus :

$Y c=a+Y i-1$

Dimana :

$a=\frac{Y_{n n}-Y_{C}}{N-1}$

Yc = nilai awal (tahun pertama)

a $\quad=$ titik potong sumbu $y$

$\mathrm{Yn} \quad=$ nilai akhir (tahun lalu)

$\mathrm{N} \quad=$ jumlah tahun

$\mathrm{Yi} \quad=$ nilai untuk tahun lalu

$\mathrm{Yi}-1$ = nilai untuk tahun-tahun sebelumnya

b) Arithmetic Geometric Curve

Metode ini merupakan metode proyeksi dengan menggunakan kurva geometris aritmatika, dengan rumus :

$Y_{c}=\frac{Y_{i}+1}{1+r}$

Dimana :

$\mathrm{Yi}+1=$ nilai untuk tahun depan

$r \quad=$ tingkat kenaikan rata-rata

c) Statistical Straight Line

Metode ini merupakan metode proyeksi dengan menggunakan statistik garis lurus, dengan rumus :

$Y c=a+b x$

Dimana :

$a=\frac{\sum Y}{n}-b \frac{\sum X}{n}$

$b=\frac{n \sum X Y-\sum X \sum Y}{n \sum X^{2}-\left(\sum X\right)^{2}}$

Keterangan :

Yc = nilai terhitung dari variabel yang akan diprediksi (variabel terikat)

a $\quad=$ titik potong sumbu $\mathrm{y}$

$\mathrm{b} \quad=$ kemiringan garis regresi

$\Sigma \quad=$ tanda penjumlahan total

$\mathrm{X} \quad=$ nilai variabel bebas

$\mathrm{Y} \quad=$ nilai variabel terikat

$\mathrm{n} \quad=$ jumlah data atau pengamatan

d) Statistical Parabolic (Trend Parabolik)

Pada penelitian ini metode yang akan dibahas adalah metode proyeksi statistical parabolic (Trend Parabolik). Penjelasan metode ini akan dijabarkan pada pembahasan di Metode Penelitian. 


\section{B. Metode Penelitian}

Metode Penelitian yang digunakan adalah metode Trend Parabolik. Metode ini mampu melakukan prediksi berdasarkan data yang telah lampau (times series). Sedangkan metode pengumpulan data yang digunakan adalah metode kuantitatif, yakni berupa data Indeks Pembangunan Manusia. Trend kuadratik merupakan deret waktu berupa dengan data berupa garis parabola. Trend parabolik (kuadratik) adalah trend yang nilai variabel tak bebasnya naik atau turun secara linier atau terjadi parabola bila datanya dibuat scatter plot (hubungan variabel dependen dan independen adalah kuadratik).

Metode Trend Parabolik digunakan untuk memproyeksi data historis ke arah garis lengkung yang berbentuk parabola. Adapun rumus yang digunakan antara lain :

$\mathrm{Yc}=\mathrm{a}+\mathrm{bX}+\mathrm{c} \mathrm{X}^{2}$

Dimana :

$$
\begin{aligned}
a & =\frac{\left(\sum X^{4}\right)\left(\sum Y\right)-\left(\sum X^{2}\right)\left(\left(\sum X^{2} Y\right)\right.}{n\left(\sum X^{4}\right)-n\left(\sum X^{2}\right)^{2}} \\
b & =\frac{\sum X Y}{\sum X^{2}} \\
c & =\frac{n\left(\sum X^{2} Y\right)-\left(\sum X^{2}\right)\left(\sum Y\right)}{n\left(\sum X^{4}\right)-\left(\sum X^{2}\right)^{2}}
\end{aligned}
$$

Keterangan :

Yc = nilai terhitung dari variabel yang akan diprediksi (variabel terikat)

a $\quad=$ titik potong sumbu $\mathrm{y}$

$\mathrm{b} \quad=$ kemiringan garis regresi

$\Sigma \quad=$ tanda penjumlahan total

$\mathrm{X} \quad=$ nilai variabel bebas

$\mathrm{Y} \quad=$ nilai variabel terikat

$\mathrm{n} \quad=$ jumlah data atau pengamatan

[13], [14]

\section{Sumber Data}

Sumber data adalah data IPM di Indonesia tahun 2010-2018 (dapat dilihat pada Tabel 1), yang bersumber dari website Badan Pusat Statistik Indonesia [8].

\section{Tahapan Penelitian}

Tahapan penelitian penting dilakukan dengan tujuan untuk mencapai hasil yang terbaik. Gambar 2 berikut merupakan tahapan dari penelitian ini.

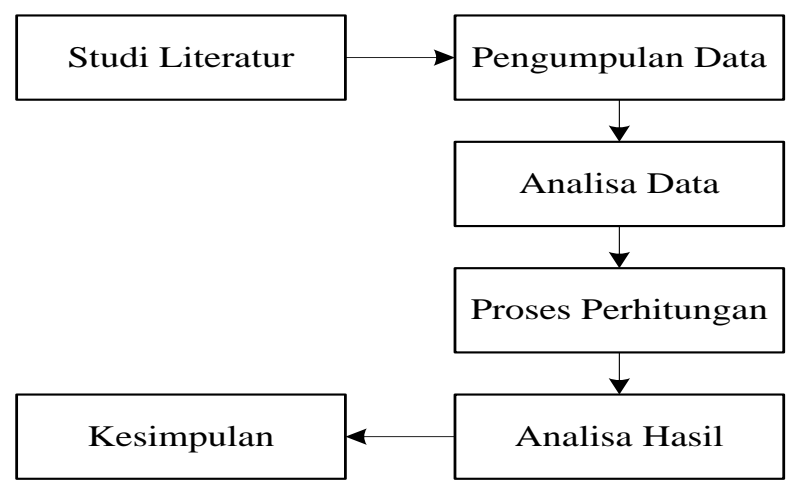

Gambar 1. Tahapan Penelitian

Pada gambar 1 dapat dijabarkan bahwa : Studi Literatur berarti melakukan analisa data literatur yang diperoleh dengan harapan memperoleh suatu kesimpulan yang lebih terukur dan terarah terhadap masalah yang jadi pembahasan. Pengumpulan data berarti mengambil data yang akan diteliti dari sumber-sumber yang tepat, dalam hal ini Badan Pusat Statistik Indonesia. Kemudian 
masuk ke tahapan analisa data, analisa data merupakan tahapan yang meliputi pengolahan data yang telah diperoleh menjadi data stasioner yang dapat digunakan menjadi variabel dalam penelitian ini. Setelah itu dilanjutkan dengan proses perhitungan menggunakan Trend Parabolik yang nantinya akan menghasilkan data proyeksi, setelah itu hasil proyeksi akan dianalisis dengan data asli (data awal), apakah hasilnya mendekati atau tidak. Setelah itu dapat diambil kesimpulan apakah metode Trend Parabolik baik digunakan untuk melakukan proyeksi Indeks Pembangunan Manusia.

\section{E. Variabel Penelitian}

Variabel penelitian yang digunakan adalah data Indeks Pembangunan Manusia di Indonesia tahun 2010 hingga tahun 2018.

\section{HASIL DAN PEMBAHASAN}

\section{A. Data Indeks Pembangunan Manusia di Indonesia}

Tabel 2 berikut ini merupakan data IPM di Indonesia tahun 2010-2018. Data ini diambil berdasarkan data Indonesia secara umum berdasarkan Tabel 1.

Tabel 2. Indeks Pembangunan Manusia di Indonesia

\begin{tabular}{cc}
\hline Tahun & Nilai Indeks Pembangunan Manusia (IPM) di Indonesia \\
\hline 2010 & 66,53 \\
2011 & 67,09 \\
2012 & 67,70 \\
2013 & 68,31 \\
2014 & 68,90 \\
2015 & 69,55 \\
2016 & 70,18 \\
2017 & 70,81 \\
2018 & 71,39 \\
\hline
\end{tabular}

\section{B. Perhitungan dengan Metode Jumlah Kuadrat Terkecil}

Metode Kuadrat Terkecil (Least Square) merupakan metode menghitung persamaan Trend Linear yang menghasilkan Deviasi Kuadrat. Metode kuadrat terkecil akan memberikan jumlah kuadrat deviasi vertikal (tegak) dari titik - titik observasi ke garis regresi tersebut sekecil mungkin, atau dengan kata lain metode kuadrat terkecil memberikan $\Sigma(Y i-\hat{Y}) 2=\sum(e i) 2$ yang terkecil [15]-[17]. Berikut ini akan dijabarkan perhitungan data Indeks Pembangunan Manusia di Indonesia dengan metode (The Least Square's Method). Perhitungan ini harus dilakukan lebih dahulu untuk memperoleh nilai a, b dan c sebelum dilakukan proyeksi terhadap data IPM dengan menggunakan Metode proyeksi statistical parabolic (Trend Parabolik).

Tabel 3. Perhitungan dengan Metode Jumlah Kuadrat Terkecil (The Least Square's Method)

\begin{tabular}{ccccccc}
\hline Tahun & Nilai IPM $(\mathbf{Y})$ & $\mathbf{X}$ & $\mathbf{X}^{\mathbf{2}}$ & $\mathbf{X}^{\mathbf{4}}$ & $\mathbf{X Y}$ & $\mathbf{X}^{2} \mathbf{Y}$ \\
\hline 2010 & 66,53 & -4 & 16 & 256 & -266 & 1064 \\
2011 & 67,09 & -3 & 9 & 81 & -201 & 604 \\
2012 & 67,70 & -2 & 4 & 16 & -135 & 271 \\
2013 & 68,31 & -1 & 1 & 1 & -68 & 68 \\
2014 & 68,90 & 0 & 0 & 0 & 0 & 0 \\
\hline
\end{tabular}




\begin{tabular}{ccccccc}
\hline Tahun & Nilai IPM $(\mathbf{Y})$ & $\mathbf{X}$ & $\mathbf{X}^{\mathbf{2}}$ & $\mathbf{X}^{\mathbf{4}}$ & $\mathbf{X Y}$ & $\mathbf{X}^{\mathbf{2}} \mathbf{Y}$ \\
\hline 2015 & 69,55 & 1 & 1 & 1 & 70 & 70 \\
2016 & 70,18 & 2 & 4 & 16 & 140 & 281 \\
2017 & 70,81 & 3 & 9 & 81 & 212 & 637 \\
2018 & 71,39 & 4 & 16 & 256 & 286 & 1142 \\
\hline $\boldsymbol{\Sigma}$ & $\mathbf{6 2 0}$ & $\mathbf{0}$ & $\mathbf{6 0}$ & $\mathbf{7 0 8}$ & $\mathbf{3 7}$ & $\mathbf{4 1 3 7}$ \\
\hline
\end{tabular}

Keterangan :

$\Sigma Y=620($ Diperoleh dari total keseluruhan nilai IPM(Y))

$\mathrm{X}=-4,-3,-2,-1,0,1,2,3,4$

Diperoleh dari rumus :

$$
X=\frac{\text { TahunDasar-TahunTengah }}{\text { Interval }}
$$

Tahun Dasar adalah tahun 2010, sedangkan Tahun tengah adalah tahun 2014. Sehingga :

$X \quad=2010-2014 / 1=-4$

$X \quad=2011-2014 / 1=-3$ (Begitu seterusnya hingga $X=4)$

$\Sigma X=0$ (diperoleh dari total keseluruhan nilai $X$ )

$X^{2} \quad=16,9,4$ dan seterusnya (Diperoleh dari nilai $X{ }^{*} X$ )

$\Sigma X^{2}=60$ (diperoleh dari total keseluruhan nilai $\left.X^{2}\right)$

$X^{4} \quad=256,81$ dan seterusnya (Diperoleh dari nilai $X^{2 *} X^{2}$ )

$\Sigma X^{4} \quad=708$ (diperoleh dari total keseluruhan nilai $X^{4}$ )

$X Y \quad=-266,-201$ dan seterusnya (Diperoleh dari nilai $X * Y$ )

$\Sigma X Y=37$ (diperoleh dari total keseluruhan nilai $X Y$ )

$X^{2} Y=1064,604$ dan seterusnya (Diperoleh dari nilai $X^{2 *} Y$ )

$\Sigma X^{2} Y=4137$ (diperoleh dari total keseluruhan nilai $X^{2} Y$ )

\section{Perhitungan Proyeksi dengan Metode Statistical Parabolic}

Langkah selanjutnya yang harus dilakukan setelah data dihitung dengan menggunakan Metode Jumlah Kuadrat Terkecil (The Least Square's Method) adalah mencari nilai a, b dan c yang merupakan variabel nilai yang akan digunakan untuk melakukan proyeksi nantinya. Untuk mencari nilai $\mathrm{a}, \mathrm{b}$ dan $\mathrm{c}$ harus berdasarkan hasil perhitungan pada Tabel 3 menggunakan rumus berikut:

$$
\begin{aligned}
& a=\frac{\Sigma X^{4}(\Sigma Y)-\Sigma X^{2}\left(\Sigma X^{2} Y\right)}{n\left(\Sigma X^{4}\right)-\left(\Sigma X^{2}\right)^{2}}=\frac{708(620)-60(4137)}{9(708)-(60)^{2}}=68,92 \\
& b=\frac{\Sigma X Y}{\Sigma X^{2}}=\frac{4137}{60}=0,61 \\
& c=\frac{n\left(\Sigma X^{2} Y\right)-\Sigma X^{2}(\Sigma Y)}{n\left(\Sigma X^{4}\right)-\left(\Sigma X^{2}\right)^{2}}=\frac{9(4137)-60(620)}{9(708)-(60)^{2}}=0,0026
\end{aligned}
$$

Setelah nilai $\mathrm{a}, \mathrm{b}$ dan $\mathrm{c}$ telah diperoleh, selanjutnya adalah tahap melakukan proyeksi data dengan menggunakan rumus :

$Y c=a+b X+c X 2$

seperti yang sudah dijelaskan sebelumnya pada persamaan (1). Perhitungan proyeksi dengan metode proyeksi Statistical Parabolic (Trend Parabolik) dapat dilihat pada tabel berikut.

Tabel 4. Perhitungan dengan statistical parabolic

\begin{tabular}{ccccccccccc}
\hline Tahun & $\mathbf{X}$ & $\mathbf{a}$ & $\mathbf{b}$ & $\mathbf{c}$ & $\mathbf{b X}$ & $\mathbf{X}^{2}$ & $\mathbf{c X}^{2}$ & Proyeksi (Yc) & Data Asli & Selisih \\
\hline 2010 & -4 & 68,92 & 0,61 & 0,0026 & $-2,45$ & 16 & 0,04 & 66,51 & 66,53 & 0,02 \\
2011 & -3 & 68,92 & 0,61 & 0,0026 & $-1,84$ & 9 & 0,02 & 67,11 & 67,09 & 0,02
\end{tabular}




\begin{tabular}{ccccccccccc}
\hline Tahun & $\mathbf{X}$ & $\mathbf{a}$ & $\mathbf{b}$ & $\mathbf{c}$ & $\mathbf{b X}$ & $\mathbf{X}^{2}$ & $\mathbf{c X}^{2}$ & Proyeksi (Yc) & Data Asli & Selisih \\
\hline 2012 & -2 & 68,92 & 0,61 & 0,0026 & $-1,23$ & 4 & 0,01 & 67,71 & 67,70 & 0,01 \\
2013 & -1 & 68,92 & 0,61 & 0,0026 & $-0,61$ & 1 & 0,00 & 68,31 & 68,31 & 0,00 \\
2014 & 0 & 68,92 & 0,61 & 0,0026 & 0,00 & 0 & 0,00 & 68,92 & 68,90 & 0,02 \\
2015 & 1 & 68,92 & 0,61 & 0,0026 & 0,61 & 1 & 0,00 & 69,54 & 69,55 & 0,01 \\
2016 & 2 & 68,92 & 0,61 & 0,0026 & 1,23 & 4 & 0,01 & 70,16 & 70,18 & 0,02 \\
2017 & 3 & 68,92 & 0,61 & 0,0026 & 1,84 & 9 & 0,02 & 70,79 & 70,81 & 0,02 \\
2018 & 4 & 68,92 & 0,61 & 0,0026 & 2,45 & 16 & 0,04 & 71,42 & 71,39 & 0,03 \\
\hline
\end{tabular}

Keterangan :

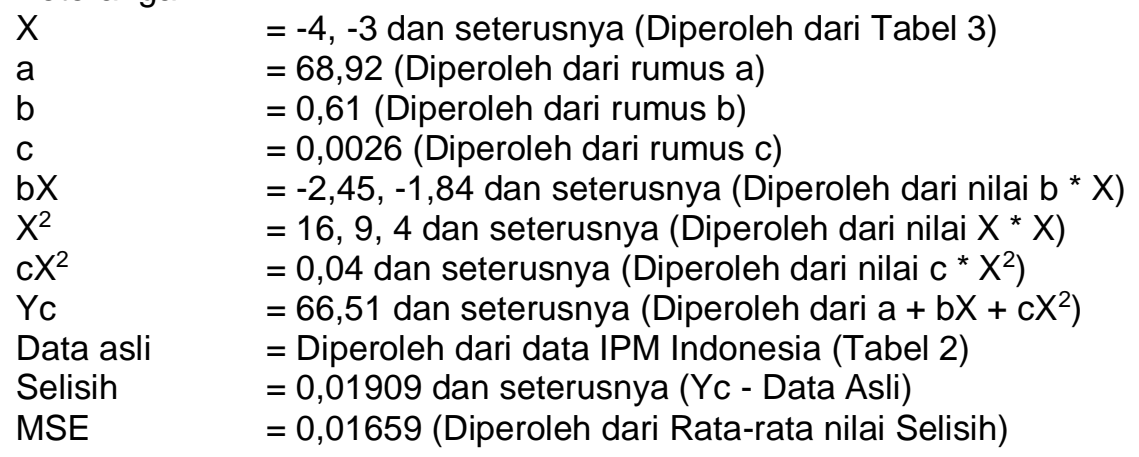

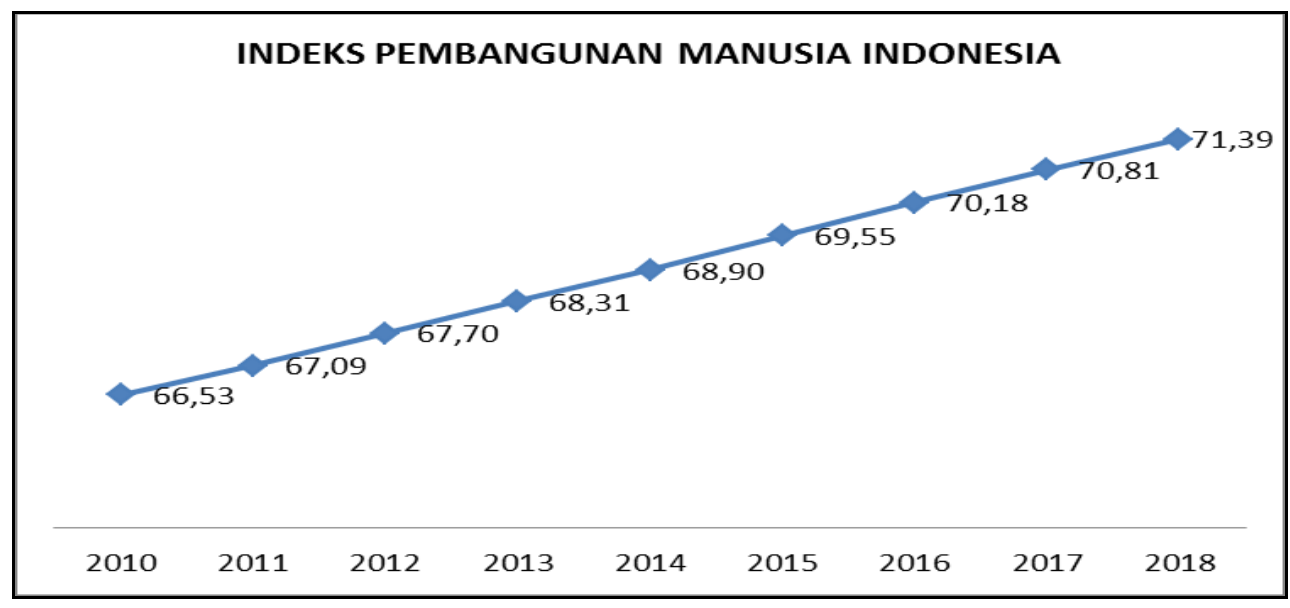

Gambar 1. Grafik Data Asli Indeks Pembangunan Manusia di Indonesia

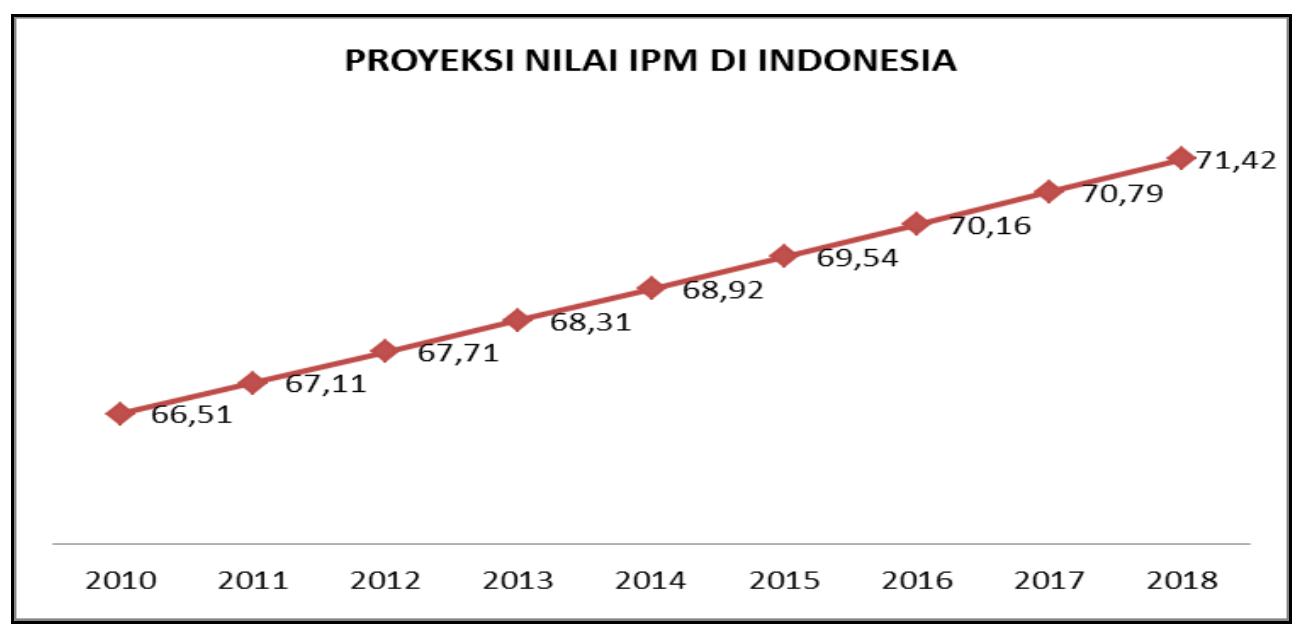

Gambar 2. Grafik Data Proyeksi Indeks Pembangunan Manusia di Indonesia 
Pada gambar 1 dan 2 dapat dilihat grafik selisih antara data asli Indeks Pembangunan Manusia (IPM) di Indonesia dengan data hasil proyeksi yang bentuknya tidak berbeda jauh. Pada tahun 2010 nilai Indeks Pembangunan Manusia di Indonesia berdasarkan data asli sebesar 66,53, sedangkan berdasarkan data proyeksi dengan menggunakan metode Statistical Parabolic (Trend Parabolik) sebesar 66,53 yang berarti terjadi selisih sebesar 0,02. Pada tahun 2011 nilai Indeks Pembangunan Manusia di Indonesia berdasarkan data asli sebesar 67,09, sedangkan berdasarkan data proyeksi dengan menggunakan metode Statistical Parabolic (Trend Parabolik) sebesar 67,11 yang berarti terjadi selisih sebesar 0,02. Pada tahun 2012 nilai Indeks Pembangunan Manusia di Indonesia berdasarkan data asli sebesar 67,70 , sedangkan berdasarkan data proyeksi dengan menggunakan metode Statistical Parabolic (Trend Parabolik) sebesar 67,71 yang berarti terjadi selisih sebesar 0,01. Pada tahun 2013 nilai Indeks Pembangunan Manusia di Indonesia berdasarkan data asli sebesar 68,31 , sedangkan berdasarkan data proyeksi dengan menggunakan metode Statistical Parabolic (Trend Parabolik) sebesar 68,31 yang berarti data asli dengan data hasil proyeksi tidak mengalami perbedaan. Pada tahun 2014 nilai Indeks Pembangunan Manusia di Indonesia berdasarkan data asli sebesar 68,90, sedangkan berdasarkan data proyeksi dengan menggunakan metode Statistical Parabolic (Trend Parabolik) sebesar 68,92 yang berarti terjadi selisih sebesar 0,02. Pada tahun 2015 nilai Indeks Pembangunan Manusia di Indonesia berdasarkan data asli sebesar 69,55, sedangkan berdasarkan data proyeksi dengan menggunakan metode Statistical Parabolic (Trend Parabolik) sebesar 69,54 yang berarti terjadi selisih sebesar 0,01. Pada tahun 2016 nilai Indeks Pembangunan Manusia di Indonesia berdasarkan data asli sebesar 70,18 , sedangkan berdasarkan data proyeksi dengan menggunakan metode Statistical Parabolic (Trend Parabolik) sebesar 70,16 yang berarti terjadi selisih sebesar 0,02. Pada tahun 2017 nilai Indeks Pembangunan Manusia di Indonesia berdasarkan data asli sebesar 70,81, sedangkan berdasarkan data proyeksi dengan menggunakan metode Statistical Parabolic (Trend Parabolik) sebesar 70,79 yang berarti terjadi selisih sebesar 0,02. Pada tahun 2018 nilai Indeks Pembangunan Manusia di Indonesia berdasarkan data asli sebesar 71,39 , sedangkan berdasarkan data proyeksi dengan menggunakan metode Statistical Parabolic (Trend Parabolik) sebesar 71,42 yang berarti terjadi selisih sebesar 0,03. Dengan demikian maka nilai rata-rata dari selisih antara data asli dengan data proyeksi sebesar 0,02 .

\section{Hasil Proyeksi}

Hasil proyeksi Indeks Pembangunan Manusia di Indonesia dengan menggunakan metode Statistical Parabolic (Trend Parabolik) untuk tahun 2019-2027 dapat dilihat pada tabel 5. Proyeksi dilakukan selama 9 tahun (2019-2027), karena data awal yang diperoleh dari Badan Pusat Statistik Indonesia juga 9 tahun (2010-2018). Variabel X bernilai 5 hingga 13, yakni diperoleh dari perhitungan seperti yang tertera pada persamaan (10)

Tabel 5. Proyeksi IPM Tahun 2019-2027

\begin{tabular}{ccccccccc}
\hline Tahun & $\mathbf{X}$ & $\mathbf{a}$ & $\mathbf{b}$ & $\mathbf{c}$ & $\mathbf{b X}$ & $\mathbf{X}^{\mathbf{2}}$ & $\mathbf{c X}^{\mathbf{2}}$ & Hasil Proyeksi \\
\hline 2019 & 5 & 68,92 & 0,61 & 0,0026 & 3,07 & 25 & 0,06 & 72,05 \\
2020 & 6 & 68,92 & 0,61 & 0,0026 & 3,68 & 36 & 0,09 & 72,70 \\
2021 & 7 & 68,92 & 0,61 & 0,0026 & 4,29 & 49 & 0,13 & 73,34 \\
2022 & 8 & 68,92 & 0,61 & 0,0026 & 4,91 & 64 & 0,17 & 74,00 \\
2023 & 9 & 68,92 & 0,61 & 0,0026 & 5,52 & 81 & 0,21 & 74,65 \\
2024 & 10 & 68,92 & 0,61 & 0,0026 & 6,13 & 100 & 0,26 & 75,32 \\
2025 & 11 & 68,92 & 0,61 & 0,0026 & 6,75 & 121 & 0,31 & 75,98 \\
2026 & 12 & 68,92 & 0,61 & 0,0026 & 7,36 & 144 & 0,37 & 76,66 \\
2027 & 13 & 68,92 & 0,61 & 0,0026 & 7,97 & 169 & 0,44 & 77,33 \\
\hline
\end{tabular}

Berdasarkan hasil proyeksi Indeks Pembangunan Manusia (IPM) yang ada pada tabel 5, dapat dilihat bahwa trend Indeks Pembangunan Manusia (IPM) mengalami kenaikan, meski tidak terlalu signifikan. Tetapi hal ini cukup membuktikan bahwa metode Statistical Parabolic (Trend Parabolik) baik digunakan untuk memproyeksi data Indeks Pembangunan Manusia (IPM) di Indonesia, karena hasil proyeksi trend kenaikannya tidak terlalu mencolok pada tiap tahun nya dan tidak berbeda jauh. 


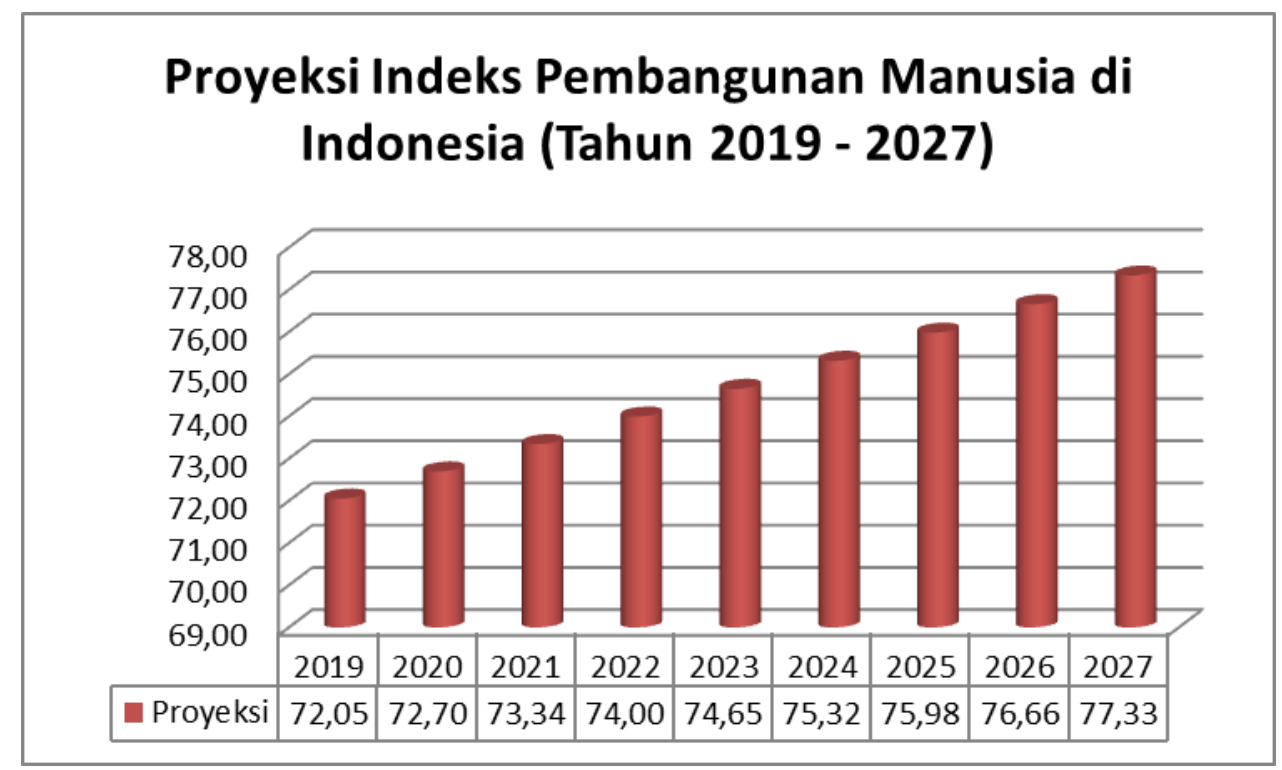

Gambar 3. Grafik Proyeksi Indeks Pembangunan Manusia di Indonesia (Tahun 2019-2027)

Pada gambar 3 dapat dilihat grafik nilai proyeksi Indeks Pembangunan Manusia (IPM) di Indonesia untuk tahun 2019 hingga 2027. Pada tahun 2019 nilai proyeksi Indeks Pembangunan Manusia (IPM) sebesar 72,05 atau meningkat 0,66 dibandingkan data asli tahun 2018 yang bernilai 71,39. Pada tahun 2020 nilai proyeksi Indeks Pembangunan Manusia (IPM) sebesar 72,70 atau meningkat 0,65 dibandingkan data proyeksi tahun 2019 yang bernilai 72,05. Pada tahun 2021 nilai proyeksi Indeks Pembangunan Manusia (IPM) sebesar 73,34 atau meningkat 0,64 dibandingkan data proyeksi tahun 2020 yang bernilai 72,70. Pada tahun 2022 nilai proyeksi Indeks Pembangunan Manusia (IPM) sebesar 74,00 atau meningkat 0,66 dibandingkan data proyeksi tahun 2021 yang bernilai 73,34. Pada tahun 2023 nilai proyeksi Indeks Pembangunan Manusia (IPM) sebesar 74,65 atau meningkat 0,65 dibandingkan data proyeksi tahun 2023 yang bernilai 74,00. Pada tahun 2024 nilai proyeksi Indeks Pembangunan Manusia (IPM) sebesar 75,32 atau meningkat 0,67 dibandingkan data proyeksi tahun 2023 yang bernilai 74,65. Pada tahun 2025 nilai proyeksi Indeks Pembangunan Manusia (IPM) sebesar 75,98 atau meningkat 0,66 dibandingkan data proyeksi tahun 2024 yang bernilai 75,32. Pada tahun 2026 nilai proyeksi Indeks Pembangunan Manusia (IPM) sebesar 76,66 atau meningkat 0,68 dibandingkan data proyeksi tahun 2025 yang bernilai 75,98. Pada tahun 2027 nilai proyeksi Indeks Pembangunan Manusia (IPM) sebesar 77,33 atau meningkat 0,67 dibandingkan data proyeksi tahun 2026 yang bernilai 76,66. Dengan demikian rata-rata kenaikan nilai Indeks Pembangunan Manusia (IPM) berdasarkan data proyeksi sebesar 0,66. Berdasarkan grafik yang ditampilkan pada gambar 3, trend nilai Indeks Pembangunan Manusia (IPM) cenderung mengalami kenaikan, tetapi nilai nya tidak terlalu besar.

\section{SIMPULAN DAN SARAN}

Berdasarkan hasil dan pembahasan yang telah dijabarkan dalam artikel ini, maka dapat diambil beberapa kesimpulan bahwa metode Trend Parabolik sangat baik digunakan untuk melakukan proyeksi terhadap Indeks Pembangunan Manusia di Indonesia. Hal ini karena setelah dilakukan pengujian secara Matematika dengan membandingkan Data Asli dengan Data Hasil Proyeksi, tidak terlalu jauh berbeda (Data Hasil Proyeksi mendekati nilai Data Asli) dengan MSE sebesar 0.02, dengan demikian metode proyeksi statistical parabolic (Trend Parabolik) baik digunakan untuk memproyeksi data Indeks Harga Konsumen di Indonesia untuk tahun 2019 dan tahun-tahun selanjutnya. Setelah dilakukan perhitungan dengan Trend Prabolik, hasil proyeksi data Indeks Pembangunan Manusia di Indonesia untuk tahun 2019 hingga tahun 2027 juga mengalami trend yang selalu naik, walaupun tidak terlalu signifikan. Untuk penelitian selanjutnya penulis menyarankan untuk memproyeksi Indeks Pembangunan Manusia ini dengan metode Statistical Parabolic (Trend Parabolik) tidak hanya di Indonesia secara umum, tetapi berdasarkan seluruh provinsi, untuk lebih menguji keakuratan proyeksi dari metode ini. 


\section{UCAPAN TERIMAKASIH}

Ucapan terima kasih kami sampaikan kepada Direktorat Riset dan Pengabdian Masyarakat, Direktorat Jenderal Penguatan Riset dan Pengembangan Kementerian Riset, Teknologi dan Pendidikan Tinggi atas pendanaan Penelitian Dosen Pemula (PDP) tahun pelaksanaan 2019.

\section{DAFTAR PUSTAKA}

[1] N. Dewi, Y. Yusuf, and R. Y. lyan, "Pengaruh kemiskinan dan pertumbuhan ekonomi terhadap indeks pembangunan manusia di provinsi riau," Jurnal JOM Fekon, vol. 4, no. 1, pp. 870-882, 2017.

[2] S. P. Siregar and A. Wanto, "Analysis of Artificial Neural Network Accuracy Using Backpropagation Algorithm In Predicting Process (Forecasting)," International Journal Of Information System \& Technology, vol. 1, no. 1, pp. 34-42, 2017.

[3] I. D. Syahputra and A. Karim, "Perbandingan Metode Ordinary Least Square (OLS) dan Regresi Robust," in Seminar Nasional Pendidikan, Sains dan Teknologi Fakultas Matematika dan IImu Pengetahuan Alam Universitas Muhammadiyah Semarang, 2015, vol. 3, no. 1, pp. 127-31.

[4] R. U. Harahap, "Pengaruh Dana Alokasi Umum, Dana Alokasi Khusus, dan Dana Bagi Hasil Terhadap Indeks Pembangunan Manusia Pada Kab./Kota Propinsi Sumatera Utara," KITABAH - Jurnal Akuntansi dan Keuangan Syariah, vol. 1, no. 1, pp. 118-130, 2017.

[5] M. Pangestika and E. Widodo, "Analisis Regresi Panel Terhadap Faktor-Faktor Yang Mempengaruhi Indeks Pembangunan Manusia Di Kabupaten/Kota D.I.Yogyakarta," in Seminar Nasional dan The 4th Call for Syariah Paper, 2017, pp. 198-205.

[6] A. Wanto, "Optimasi Prediksi Dengan Algoritma Backpropagation Dan Conjugate Gradient Beale-Powell Restarts," Jurnal Teknologi dan Sistem Informasi, vol. 3, no. 3, pp. 370-380, Jan. 2018.

[7] A. Wanto, "Penerapan Jaringan Saraf Tiruan Dalam Memprediksi Jumlah Kemiskinan Pada Kabupaten/Kota Di Provinsi Riau," Kumpulan jurnaL IImu Komputer (KLIK), vol. 5, no. 1, pp. 6174, 2018.

[8] BPS, "Indeks Pembangunan Manusia menurut Provinsi, 2010-2018 (Metode Baru)," Badan Pusat Statistik (BPS) Indonesia, 2018. [Online]. Available: https://www.bps.go.id/dynamictable/2016/06/16/1211.

[9] R. M. Putra, E. Asril, and Taslim, "Prediksi Indeks Pembangunan Manusia Dengan Menggunakan Decision Tree C4.5 Di Kabupaten Kampar," 2018.

[10] A. H. Yanottama and Wardono, "Proyeksi PDRB Atas Dasar Harga Berlaku Menggunakan Metode Trend Linier, Parabolik dan Eksponensial," in Seminar Nasional Pendidikan, Sains dan Teknologi Fakultas Matematika dan IImu Pengetahuan Alam Universitas Muhammadiyah Semarang, 2017, pp. 39-45.

[11] B. Sutikno, A. Faruk, and O. Dwipurwani, "Penerapan Regresi Data Panel Komponen Satu Arah untuk Menentukan Faktor-Faktor yang Mempengaruhi Indeks Pembangunan Manusia," Jurnal Matematika Integratif, vol. 13, no. 1, pp. 1-10, 2017.

[12] Rahmawati, "Model Trend untuk Peramalan Jumlah Penduduk," Jurnal JTRISTE, vol. 2, no. 2, pp. 46-52, 2015.

[13] D. Rahmawati, Darmawijoyo, and Hapizah, "Desain Pembelajaran Materi Fungsi Linier Menggunakan Pemodelan Matematika," Jurnal Pendidikan Matematika FKIP, vol. 7, no. 1, pp. 65-79, 2018.

[14] D. Kurniawati and T. S. Pratiwi, "Analisis Anggaran Penjualan Sebagai Alat Perencanaan Laba Pada PT Wahana Persada Karton Palembang," Jurnal IImiah Ekonomi Global Masa Kini, vol. 8, no. 1, pp. 61-66, 2017.

[15] L. Suwita, "Metode Least Square dalam Mengukur Trend Penjualan Pada Home Industry Bengkel Sendal Thostee Bukittinggi," Jurnal Menara IImu, vol. XII, no. 79, pp. 54-60, 2018.

[16] A. Frederika and I. A. R. Widhiawati, "Analisis Produktivitas Metode Pelaksanaan Pengecoran Beton Ready Mix pada Balok dan Pelat Lantai Gedung," Jurnal Spektran, vol. 5, no. 1, pp. 5663, 2017

[17] Z. Setiarini and E. Listyani, "Analisis Regresi Robust Estimasi-S Menggunakan Pembobot Welsch dan Tukey Bisquare," Jurnal Matematika, vol. 6, no. 1, pp. 48-55, 2017. 